\title{
Analysis of international experience in the field of building information modelling of transport infrastructure objects
}

\author{
Maxim Zheleznov ${ }^{1 *}$, Liubov Adamtsevich ${ }^{1}$, Pavel Vorobev ${ }^{1}$, and Zoya Filimonova ${ }^{2}$ \\ ${ }^{1}$ Moscow State University of Civil Engineering, Yaroslavskoe shosse, 26, Moscow, 129337, Russia \\ ${ }^{2}$ Russian University of Transport, Obraztsova street, 9, Moscow, Russia
}

\begin{abstract}
In this paper, the authors consider the current state and level of implementation of building information modeling applied to transport infrastructure at the stages of their life cycle in Russia and abroad. Possible prerequisites for the transfer of knowledge and technologies of building information modeling from the civil and industrial facilities to the field of transport construction are highlighted according to the accumulated experience in the design, construction and operation of such facilities in various countries and Russia. Special emphasis is placed on examples of the world's largest implemented or ongoing projects for the construction of transport infrastructure. The experience of implementing these projects was analyzed from the point of view of the software used in relation to all stages of the life cycle of transport infrastructure objects: design, construction and subsequent operation. The prospects for the development of data exchange formats in the context of the existing problem of mutual integration of BIM and GIS for transport infrastructure objects to ensure their complementarity and compatibility are also considered. The functional levels of the use of various software within the framework of companies implementing project activities using information modeling technologies are highlighted. A list of criteria characterizing the level of information modeling technologies integration to transport infrastructure objects into the activities of participants in the life cycle of these objects is highlighted. A review of the regulatory framework of information modeling in construction in Russia is carried out, and the main differences in this area with the regulatory regulation of this area in the European Union are noted. Conclusions are made about the key reference points for the development of information modeling of transport infrastructure facilities on a national scale, leading customer companies and contractors.
\end{abstract}

\section{Introduction}

Building information modeling (BIM) technologies are actively implemented in the construction of civil and industrial facilities around the world [1, 2, 3, 4] and in Russia [5, $6,7,8]$. Their impact on the cost, construction time, the possibility of eliminating errors in

* Corresponding author: ZheleznovMM@mgsu.ru 
the design and the transparency of the construction process itself have been evaluated by many research groups $[3,9,10,11]$, as well as directly during work on many large infrastructure facilities $[4,5,12,13]$.

At the same time, the introduction of information modeling for transport infrastructure facilities at the present stage is largely different from the experience of using these technologies in civil and industrial construction $[14,15]$. This is due both to the need to create a unified model for its geographically distributed parts, located at a considerable distance from each other, and to the widespread development in the transport industry of the use of geographic information systems (GIS) tools $[16,17]$.

In this regard, the purpose of the paper is to review the existing experience, technologies and knowledge in this area in order to form the conceptual foundations for the implementation of information modeling technologies in the construction of transport infrastructure (railway infrastructure - in particular) on the territory of the Russian Federation. To achieve this goal, it is necessary to:

- Conduct an analysis of the world experience in the implementation of information modeling technologies in the construction of transport infrastructure facilities;

- highlight the detailed structure of design systems based on the main process events accompanying the development of the project at the stage of construction and operation;

- conduct a review of the current state of the construction and transport industries in terms of information modeling technologies in Russia;

- review the current state of ensuring data interoperability at the junction of the use of BIM and GIS technologies.

\section{Methods and materials}

\section{World experience of information modeling technologies implementation in the construction of transport infrastructure}

\section{The review of major infrastructure projects}

According to the analysis of publications from international databases, large infrastructure projects related to railway construction were identified. There are some projects with different levels of use of information modeling technologies in the world in recent years:

- RailBaltica project, European Union. This project is part of the Trans-European Transport Network (TEN-T). Within the framework of this project, the North SeaBaltic corridor is being implemented $[18,19]$. BIM technologies were applied from the very beginning of construction, with the RB Rail AS project team offering the BIM Guide to all its contractors as a unified project implementation rule. The main format for data exchange and storage is the IFC format, and the main software used is the tools of the Bentley Systems ecosystem.

- Crossrail project, UK. Within the framework of this project, a new railway groundunderground line with a length of 117 kilometers and crossing London from west to east was laid [20]. Crossrail did not set strict requirements for the storage and exchange formats, but at the same time set strict design standards in relation to the company's internal processes and software systems. In this case, the main system for joint design was the Bentley ProjectWise system.

- Project High Speed 2, Great Britain. HS2 is a new high-speed underground-surface railway [21] connecting London, Midlands, North and Scotland and serving more than 
25 stations. As with the Crossrail project, this project established BIM design requirements for contractors and used the Bentley Systems ecosystem programs as the main programs used.

- Comprehensive development of railway infrastructure in China. China is the world leader in the implementation of high-speed rail lines. In 2019, China invested \$ 117 billion in the development of railways, increasing their length by $4,600 \mathrm{~km}$. China Railway Engineering Consulting Group, a leading construction company involved in many large infrastructure projects, has chosen Bentley Systems' shared data environment as the main tools for the program. At the same time, the Chinese division of buildingSMART, which implements the policy of standardizing BIM technologies, proposed a specialized BIM standard for IFC Rail [22].

- Comprehensive development of railway infrastructure in South Korea. Since 2016, in South Korea, when implementing projects worth more than $\$ 50$ million and all public sector projects, the use of BIM technologies has become mandatory. In this regard, the country adopted a roadmap for information modeling Rail BIM 2030 [23,24], implying a phased implementation of BIM modeling with different levels of technology maturity.

- Implementation of construction projects by Deutsche Bahn AG (Deutsche Bahn Holding), Germany. The German Federal Transport Agency has set a digital design and construction goal for all large-scale government projects from 2020. That is why Deutsche Bahn AG, the main operator of German railways, has already implemented 13 pilot projects using BIM technology and plans to scale up the experience gained in the future [25]. At the same time, in matters of organizing the digital modeling and construction process, there is a similarity with the already mentioned Crossrail project, where strict requirements were put forward for all contractors in terms of design standards in relation to common data environments and company systems.

- Implementation of construction projects by Maharashtra Metro Rail Corporation Limited (Maha Metro), India. The company is currently building two major rail projects in the cities of Nagpur and Pune, with a total length of 38,215 km and 31,254 $\mathrm{km}$, respectively. As in the case of previous projects, strict design standards were set for all contractors by the company. The company created a common data environment based on Bentley ProjectWise Design Integration and Bentley Asset Wise CDE.

Thus, two characteristic features can be noted that accompany the implementation of large infrastructure projects in the field of railway construction: the mandatory development of customer requirements for information implementation of the project (EIR), as well as the organization of a common data environment based on software systems.

\section{BIM maturity levels}

Basically, researchers distinguish several levels of BIM maturity, which are separated by the volumes used, formats and forms of exchange and use of data in the project [26, 27, 28, 29]:

- BIM 1.0. Convert 2D to 3D. It is typical for this level that most of the project participants do not work in the BIM environment, and 2D drawings remain the main means of communication.

- BIM 2.0. Parallel BIM. The second level is characterized using BIM for important parts of the project: in areas where the interaction of participants is required, areas with complex geometry.

- BIM 3.0. Integrated BIM. For the third level, it is characteristic that all the main project participants will create BIM-models and work with them. 
- BIM 4.0. Intelligent BIM (AI BIM). This phase is characterized by the accumulation and analysis of big data by integrating BIM with sensors and multiple databases, which will improve the efficiency of informed decision-making.

The main criteria for the division are the forms of exchange and use of data in the project, while in order to translate the successful experience of introducing BIM technologies from the construction of industrial and civil facilities to the construction of transport infrastructure, it is necessary to analyze a more detailed functional structure of design systems based on the identification of the main process events accompanying the development of the project at the stage of construction and operation. The authors of the study suggest a similar structure below:

1. System for downloading, accessing and exchanging technical documentation within the project (including BIM models) (Browser version of software/ Desktop version of software/ Mobile version of software);

2. Document approval (Changing file statuses/ Moving files after approval/ Electronic marking of approval in PDF / Placing QR-code on PDF with approval data/ Submission of a full-fledged electronic digital signature);

3. Viewing documentation (View 2D (-CAD) documentation / View 3D (-BIM) documentation);

4. System for generating and linking comments to documentation (On 2D (-CAD) documentation/In 3D(-BIM) models / Customizable uploading of prescriptions and acts of elimination);

5. Statement of tasks within the project (4D-modeling) (On 2D(-CAD) documentation with separation of subsections / In 3D(-BIM) models with a single parameterization and the possibility of associated changes/ With automatic generation of the Gantt chart, a high degree of detail and the ability creating and implementing dependencies);

6. Systems for the formation of measures for control of the construction site (checklists) (For routine inspections/ For acceptance of work performed / Unloading of acts for signature);

7. Comparison of documents (2D (-CAD) drawings / BIM-models);

8. Access to API for integration. (Obtaining statistics (number of files, comments, users) / Editing and creating objects in the system via desktop software / Performing actions in the system via a light client);

9. Maintenance of accounting activities (Integration with external accounting tools / Availability of built-in budget management tools / Linking accounts to contracts (including via blockchain);

10. Calculation of the scope of planned and completed work (Entering planned scope of work through external systems / Obtaining scope of work from the BIM model / Automated check of the BIM model for collisions and duplication of scope);

11. Communication with supporting surveys (Communication with laser scanning point clouds / Communication with survey results from a quadcopter/ Communication with media information from a construction site $\left(360^{\circ}\right.$ photo, video from surveillance cameras)/ Comparison of stored data in different time intervals / Visual comparison of the project condition with the actual condition at the construction site);

12. Formation of reports on the results of monitoring the construction site (Plan / fact in time / Plan / fact in terms of financial indicators/ Dynamics of work performance and accounting of workers at the construction site);

13. Preparation of as-built documentation (2D drawings / As-built BIM-models / Visualization of deviations of building structures).

Thus, it can be observed that the full-fledged implementation of information modeling has levels of maturity for each process event within the project and affects a wide range of 
both organizational issues and issues of the professional level of project participants at each stage of implementation.

The high dependence of the level of BIM technologies maturity in a project on the professional level of its performers is noted by many researchers $[30,31]$. The experience of many countries $[32,33,34,35]$ shows that the implementation of new training programs based on secondary specialized and higher educational institutions, as well as retraining and advanced training programs can effectively solve personnel issues related to the need of new competencies for all project participants. So, in Singapore, the level of $100 \%$ use of BIM in design organizations was achieved in 2015, the entire process of transformation of the industry was accompanied by the participation of a specialized training and research unit - BCA Academy. This division provides educational services at all levels: from training construction workers to training managers. And all this is in close connection with information modeling technologies, around which a new set of competencies and skills of all participants in construction projects is being formed.

\section{Main software and its' functional levels}

Within the framework of the infrastructure projects discussed above, as well as in other projects of companies presented in scientific studies [18-26, 36, 37], the used software complexes were complexes that are part of the ecosystem of products of Autodesk and Bentley Systems.

At the same time, many participants in the Russian and foreign markets note $[38,39]$ that the high quality of project execution is ensured by the presence of a wide range of software at various functional levels, the structure of which the authors of this study suggest below in Figure 1:

\begin{tabular}{|c|c|}
\hline LVL 14 & INTERACTION SYSTEMS \\
\hline LVL 13 & GENERAL DATA ENVIRONMENT \\
\hline LVL 12 & 6D-MODELLING \\
\hline LVL 11 & 5D-MODELLING \\
\hline LVL 10 & 4D-MODELLING \\
\hline LVL 9 & ANALYSIS OF A BIM-MODEL \\
\hline LVL 8 & DRAFTING ESTIMATES \\
\hline LVL 7 & ANALYSIS AND SIMULATION FROM SITE DATA \\
\hline LVL 6 & CONSTRUCTION CALCULATIONS, etc. \\
\hline LVL 5 & DESIGN OF STRUCTURES AND ENGINEERING NETWORKS \\
\hline LVL 4 & VISUALIZATION SYSTEMS \\
\hline LVL 3 & AUTOMATED DESIGN SYSTEMS \\
\hline LVL 2 & 2D-CAD GRAPHICS CREATION SYSTEMS \\
\hline LVL 1 & TEXT DOCUMENTATION EXCHANGE SYSTEMS \\
\hline LVL 0 & OPERATIONAL SYSTEMS \\
\hline
\end{tabular}

Fig. 1. Functional levels of software in relation to the tasks solved during the design and construction of facilities using information modeling technologies

At the same time, today the tasks of each functional level are solved using various software. The authors of the study distributed this software in relation to the mentioned functional levels as follows: 
0. Operating systems on the basis of which the work of the necessary software is implemented (MS Windows/ MacOS/ Linux);

1. Text documents / explanatory documentation - MS Office/ Libre Office/ Openoffice (+ Office365/ Google Docs - for cloud solutions);

1. Text documents in universal format pdf - Adobe Acrobat Pro or analogs;

2. 2D-CAD graphics - Autodesk Autocad/ Nanocad/ Zwcad;

3. Design of roads, general layout, external networks in BIM - «Робур»/ «Индоркад»/ «Кредо»/ Autodesk Civil3D/ Bentley OD;

3. Design of industrial facilities - Aveva E3D/ Bentley BD/ Intergraph/ Smartplant 3D/ Autodesk Revit;

3. Designing architecture in BIM - Revit/ ArchiCAD/ Renga;

4. Visualization and interiors - Autodesk Revit + Enscape/ Lumion/ Twinmotion/ 3dssmax + Adobe Photoshop/ Sketchup/ Blender;

5. Design of structures in the BIM environment - Autodesk Revit/ Tekla/ Allplan/ Renga;

5. Design of engineering communications in BIM - Autodesk Revit/ Renga/ Magicad/ Eplan 3D/ NanoCAD/ Model Studio CS;

6. Constructive calculations - SCAD/ Lira Soft/ Lira SAPR/ Autodesk Robot/ Sofistik;

6. Geotechnical calculations - Plaxis/ FEMModels/ Midas;

6. Hydraulic calculations on external networks - Zulu or analogs;

6. Other network calculations;

7. Processing of point clouds of laser scanning and photogrammetry - Autodesk Recap/ Leica Cyclone/ Trimble business center/ Agisoft Metashape/ Cloud compare;

7. Automatic modeling by point clouds - Leica Cloudworx/ ClearEdge3D/ Faro AsBuilt/ Scantobim;

8. Budgeting: А0/ «Грандсмета»/ «СметаВизард»/ «Адепт»;

9. Creation and analysis of the consolidated BIM model, collision checking Autodesk Navisworks/ Solibri/ BIMcollab/ Trimble Connect/ CadLib/ Autodesk BIM Collaborate/ PilotBIM;

10. 4D-modeling (construction processes) - Autodesk Navisworks/ Synhro4D/ BricsCAD;

11. 5D-modeling (distribution of construction costs in time) - Estima/ Larix/ DSX/ iTWO;

12. 6D Simulation (Model Based Operation) - Ecodomus/ Autodesk Dasher360/ Autodesk Tandem/ Sodis building FM/ Agacad BIMAxon;

13. Common data environment for design / construction / life cycle stages - Windows Server/ Autodesk Vault/ MS Sharepoint and other solutions VitroCAD/ Ingipro/ Autodesk BIM360/ PilotICE;

14. Systems of remote interaction of project participants - Zoom/ Skype/ MS Teams/ Trueconf.

Thus, it can be noted that the transition to information modeling technologies should be associated, among other things, with the development of functionality and tools within software systems. At the same time, this development can take place both through the collection and exchange of data using universal open formats, and based on the development of ecosystems of products of large developer companies. 


\section{Review of the current state of the construction and transport industries in terms of information modeling technologies in Russia}

\section{The regulation of information modeling implementation in Russia}

According to the decree of the Government of the Russian Federation dated March 5, 2021 No. 331, from January 1, 2022, for capital construction projects (CCP) financed with the involvement of funds from the budgetary system of the Russian Federation, the formation and maintenance of the CCP information model must be ensured. Moreover, the provision of this requirement is mandatory for all the main participants in the construction process: the developer, the technical customer, the person providing or preparing the investment justification, or the person responsible for the operation of the facility.

Also, other regulatory documents were previously published, the adoption of which is focused on the development of information modeling of buildings and structures in Russia:

- Decree of the Russian Federation Government of September 15, 2020 No. 1431, which approved the rules for the formation and maintenance of the information model, the composition of information, documents and materials included in the information model and presented in the form of electronic documents, requirements for the formats of these electronic documents.

- The Order of the Ministry of Construction of Russia dated December 24, 2020 No. 854 / pr, which approved the methodology for determining the cost of work on the preparation of project documentation containing materials in the form of an information model.

There is a list of set of rules that are relevant for Russia (as of March 2021) describing the requirements for the implementation of projects using information modeling technologies in construction below:

1. SR 301.1325800.2017 "Information modeling in construction. Rules for the organization of work by production and technical departments "

2. SR 328.1325800.2017 "Information modeling in construction. Rules for describing information model components."

3. SR 331.1325800.2017 "Information modeling in construction. Exchange rules between information models of objects and models used in software systems."

4. SR 333.1325800.2017 "Information modeling in construction. Rules for the formation of an information model of objects at various stages of the life cycle "

5. SR 404.1325800.2018 "Information modeling in construction. Rules for the development of project plans implemented using information modeling technology."

6. SR 471.1325800.2019 "Information modeling in construction. Quality control of construction works."

7. SR 480.1325800.2020 "Information modeling in construction. Requirements for the formation of information models of capital construction objects for the operation of apartment buildings implemented under reuse projects."

8. SR 481.1325800.2020 "Information modeling in construction. Rules of application in cost-effective design documentation for reuse and when it is linked."

It is important to note that the regulatory support of information modeling in Russia is built around the concept of an information model, as a set of files containing a certain set of data that meets certain requirements in terms of format and name. At the same time, according to ISO 19650-1: 2018, the information modeling of the EU countries is built around the concept of an "information container", which allows software developers and 
project participants not to be tied to the file data structure, but to build information modeling processes directly around the data, and not how they storage and transmission.

At the same time, it is obvious that the development of a system of state regulation of information modeling should also be accompanied by the development of a system of internal regulation and standardization of the use of BIM at the level of companies that are customers of services for the development and implementation of construction projects.

\section{Basic approaches to ensuring data interoperability}

City Geography Markup Languages (CityGML), Shape (SHP) and Industry Foundation Class (IFC) are the three most popular data exchange formats for mutual integration in Geographic Information System (GIS) and Building Information Modeling (BIM) projects [40].

At the same time, compatibility problems between them are noted, the main of which is the loss of data in the process of information transformation.

On the one hand, GIS is georeferenced topological data that allows to perform spatial analysis of the described objects, as well as to solve problems related to the optimization of paths, position and determination of the zones of influence of objects. On the other hand, BIM is not capable of such analysis, but its essence is the formation of a detailed database of object-oriented parametric information for structures and buildings, closely related to the three-dimensional model [41, 42].

During transferring information between BIM and GIS formats, the key issues are the issues of ensuring the completeness and reliability of geometric transformations, as well as the semantic transfer of information. For BIM, the representative data format is IFC, an open object-oriented data format. There are two main formats available for GIS: CityGML and Shapefile (SHP). At the same time, it is SHP that is used in applied projects, since has the property of storing parametric information, and is better suited for BIM and GIS integration.

Researchers note that the mutual integration of BIM and GIS can provide a deeper understanding of the processes accompanying the construction of facilities, which ultimately affects the quality and speed of decisions made both at the design stage and at the stages of direct construction of facilities [43]. Such integration allows to effectively manage information at the design, construction and operation stages, thus capturing all stages of the object's life cycle.

The main system for dividing the levels of integration of BIM and GIS is the division into three groups [44]:

- Data level. At this level, models and data formats are manipulated (transformed) to meet the requirements of the application used in the project. Such an approach is effective in the degree of adaptation of requirements to a specific project, but does not have the ability to scale and develop outside the framework of a specific or similar project;

- Application level. This level implements the new applications that provide the functionality integration of BIM and GIS. At the same time, the level of mutual penetration of BIM and GIS is dictated only by the needs of the project, but limited by the capabilities of the applications used;

- Process level. At this level, both BIM and GIS are involved in the workflow and are integrated.

It is difficult to achieve the last two levels today [44], and special attention at the current stage of development of mutual integration of BIM and GIS systems should be paid to the first level and the development of tools for its implementation. This is due, among other things, to the fact that the fundamental problems of the loss of semantic information 
because of the integration of BIM and GIS have not yet been resolved, the solution of which is seen only in the modification of the formats themselves to the requirements of a particular project, although in the future the focus of solving this problem will shift to the area development of universal data formats capable of lossless integration of BIM and GIS.

\section{Results}

Considering all the above, it can be concluded that the development of the transport infrastructure of regions and countries soon is inextricably linked with the introduction and application of information modeling technologies at all stages of the life cycle of transport infrastructure objects.

At the same time, the need for the transformation and development of today's formats for the exchange and storage of design data is clearly expressed. A promising solution in this area is the development of the mutual integration of formats, as well as the platforms that support their use, IFC and SHP, which, in combination with each other, provide a description of many geometric parameters of a project for wide geographic scales, as well as a full-fledged parametric filling of models.

At the same time, the software systems used for the implementation of information modeling of transport infrastructure objects remain a subject for discussion, since none of the software systems on the market today provides the functionality of work that fully satisfies all market participants, as well as the level of interoperability, requirements for which are critical in the context of integrating BIM and GIS formats with the need to preserve the benefits of both. Bentley Systems has received the best endorsements from users and companies on the market.

The considered experience of the widespread implementation of information modeling in the construction of transport infrastructure in various countries and companies allowed the authors of the study to identify several key points on the way of introducing this technology:

- The basis for the implementation and development of the use of information modeling technologies for transport infrastructure facilities at the company level should be a structural transformation in the project department associated with the emergence of the position of a BIM manager, whose responsibilities should include organizing and coordinating the joint work of project department employees with the allocation of targets for retraining and professional development of employees with the aim of a gradual transition from 2D CAD-modeling to 3D + BIM-modeling;

- The main incentive for the introduction of information modeling technologies for transport infrastructure objects should be the emergence of BIM standards (and at the company level - EIR, which are a mandatory annex to the technical task), containing a detailed set of requirements for design data (including their structure and transfer formats between stages project implementations);

- At the country level, it is necessary to ensure the implementation of educational programs based on secondary specialized and higher educational institutions, as well as programs for retraining and advanced training for specialists implementing projects using information modeling technologies for transport infrastructure facilities.

\section{Discussion}

Based on this study, the authors present the development of information modeling technologies for transport infrastructure in Russia as a process of close interaction between 
the state, companies performing the functions of a customer, executing companies in the design sphere, executing companies in the field of construction, as well as companies operating buildings and structures. The authors are convinced that the phased implementation of BIM technologies in relation to the functional levels of project activities, as well as to process events during the implementation of the project, is a criterion for the sustainable development of digital construction in the field of transport infrastructure.

The authors will direct their further research for detailing the key stages of the implementation of the transition to information modeling of transport infrastructure facilities, including determining the influencing factors on the possibility and level of implementation of a full-fledged monitoring system for these facilities using distributed sensor systems, collection and processing of big data based on BIM- models.

The reported study was funded by RFBR, Sirius University of Science and Technology, JSC Russian Railways and Educational Fund "Talent and success", project number 20-38-51013

\section{References}

1. F.H. Abanda, L. Byers, An investigation of the impact of building orientation on energy consumption in a domestic building using emerging BIM (Building Information Modelling), Energy., 97, pp. 517-527 (2016)

2. A.F. Abd Rashid, S. Yusoff, A review of life cycle assessment method for building industry, Renew. Sustain. Energy Rev., 45, pp. 244-248 (2015)

3. K. Negendahl, T.R. Nielsen, Building energy optimization in the early design stages: a simplified method, Energy Build. (2015)

4. T. Ahmad, M.J. Thaheem, Developing a residential building-related social sustainability assessment framework and its implications for BIM, Sustain. Cities Soc., 28, pp. 1-15 (2017)

5. D. Cao, H. Li, G. Wang, Impacts of isomorphic pressures on BIM adoption in construction projects, J. Constr. Eng. Manag. (2014)

6. Volkov A., Chelyshkov P., Sedov A., Application of computer simulation to ensure comprehensive security of buildings., Applied Mechanics and Materials, 409, pp. 630633 (2013)

7. Atazadeh, B., Kalantari, M., Rajabifard, A., Comparing Three Types of BIM-based Models for Managing 3D Ownership Interests in Multi-level Buildings, in: 5th International Fig. 3D Cadastre Workshop. International Federation of Surveyors (FIG), Athens, Greece, pp. 183-198 (2017)

8. Mohamad Kassem, Bilal Succar, Macro BIM adoption: Comparative market analysis, Automation in Construction, 81, Pages 286-299 (2017)

9. I.B. Kjartansdóttir, BIM Adoption in Iceland and Its Relation to Lean Construction, Master's of Science in Construction Management Master's), Reykjavík University, Reykjavík (2011)

10. M. Marzouk, S. Azab, M. Metawie, BIM-based approach for optimizing life cycle costs of sustainable buildings, J. Clean. Prod. (2018)

11. Y. Geng, W. Ji, Z. Wang, B. Lin, Y. Zhu, A review of operating performance in green buildings: energy use, indoor environmental quality and occupant satisfaction, Energy Build. (2019)

12. T. Lehtinen, Advantages and Disadvantages of Vertical Integration in the Implementation of Systemic Process Innovations: Case Studies on Implementing 
Building Information Modelling (BIM) in the Finnish Construction Industry, Master's Thesis, Aalto University (2010)

13. McGraw-Hill-Construction, The business value of BIM in Australia and New Zealand, SmartMarket Report (2014)

14. Fernando G. Bañuelos Blanco, Haibo Chen, The Implementation of Building Information Modelling in the United Kingdom by the Transport Industry, The 9th International Conference on Traffic \& Transportation Studies (ICTTS'2014), Procedia - Social and Behavioral Sciences, pp. 510 - 520, 138 (2014)

15. Ali Aryo Bawono, Christian Maximilian von Schumann, and Bernhard Lechner, Study of Building Information Modelling Implementation on Railway Infrastructure, ICCCBE 2020, LNCE 98, pp. 372-382, 2021

16. Mohammed Jawaluddeen Sani and Alias Abdul Rahman, GIS AND BIM INTEGRATION AT DATA LEVEL: A REVIEW, International Conference on Geomatics and Geospatial Technology (GGT 2018), 3-5 September 2018, Kuala Lumpur, Malaysia

17. Fabrizio D'Amico, Alessandro Calvi, Eleonora Schiattarella, Mauro Di Prete, BIM And GIS Data Integration: A Novel Approach Of Technical/Environmental DecisionMaking Process In Transport Infrastructure Design, AIIT 2nd International Congress on Transport Infrastructure and Systems in a changing world (TIS ROMA 2019), 23rd24th September 2019, Rome, Italy, Transportation Research Procedia 45, pp. 803-810 (2020)

18. RailBaltica project; Available: https://www.railbaltica.org

19. RailBaltica BIM documentation; Available: https://www.railbaltica.org/rb-rail-as-bimdocumentation/

20. Vasily Kupriyanovsky etc. BIM on the world's railways - development, examples, and standards, International Journal of Open Information Technologies, vol. 8 (2020)

21. High Speed 2 project; Available: https://www.hs2.org.uk, https://en.wikipedia.org/wiki/High_Speed_2

22. Steve Cockerell, Director Industry Marketing - Road and Rail, Bentley Systems "China Railway Sets Benchmark for Full-lifecycle BIM on Beijing-Zhangjiakou Rail Project”; Available: https:/www.cbnme.com/logistics-news/china-railway-setsbenchmark-for-full-lifecycle-bim-on-beijing-zhangjiakou-rail-project/

23. Korean Ministry of Land, Infrastructure and Transport, Korea Railroad Research Institute, Yonsei University "Rail BIM 2030 Roadmap"; Available: http://big.yonsei.ac.kr/railbim/reports/RailBIM2030Roadmap_Full_Eng_Final.pdf

24. The Rail BIM 2030 roadmap project; Available: https://www.giminternational.com/content/article/the-rail-bim-2030-roadmap-project

25. Implementation of Building Information Modeling (BIM) in the Infrastructure Division of Deutsche Bahn AG, Deutsche Bahn AG 2019, Available: https://www.deutschebahn.com/resource/blob/4114234/f17c340682cd9e8f6bfe3faae86 e0f52/BIM-Strategy-Deutsche-Bahn-en-data.pdf

26. Dmitry Zamolodchikov, Vasily Kupriyanovsky, Dmitry Namiot, German Sukonnikov, Natalia Fedorova, Petr Bubnov, "Comfortable environment and resources for passenger stations in the lifecycle of digital railways assets", International Journal of Open Information Technologies, vol. 5, (2017) 
27. Lieyun Ding, Weiguang Jiang, Ying Zhou, Cheng Zhou, Sheng Liu, BIM-based tasklevel planning for robotic brick assembly through image-based $3 D$ modeling, Advanced Engineering Informatics, Volume 43 (2020)

28. Idris Othman, Yasser Yahya Al-Ashmori, Yani Rahmawati, Y.H. Mugahed Amran, Mohammed Ali Mohammed Al-Bared, The level of Building Information Modelling (BIM) Implementation in Malaysia, Ain Shams Engineering Journal, Volume 12, Pages 455-463 (2021)

29. Moumita Das, Xingyu Tao, Jack C.P. Cheng, BIM security: A critical review and recommendations using encryption strategy and blockchain, Automation in Construction, Volume 126 (2021)

30. Ali Abbas, Zia Ud Din, Rizwan Farooqui, Integration of BIM in Construction Management Education: An Overview of Pakistani Engineering Universities, Procedia Engineering, Volume 145, Pages 151-157 (2016)

31. Jan Fridrich, Karel Kubečka, BIM - The Process of Modern Civil Engineering in Higher Education, Procedia - Social and Behavioral Sciences, Volume 141, Pages 763767 (2014)

32. J. Zolotova, N. Vatin, E. Tuchkevich, Rechinsky. A. Autodesk Revit - Key To Successful Training Of Highly Qualified Civil Engineers, Applied Mechanics and Materials, 725726, pp. 1617-1625 (2015)

33. E. Tuchkevich, A. Rechinsky, N. Vatin, J. Zolotova, V. Tuchkevich, The Benefits Of Authorized Training Center Autodesk For Higher Education Institutions, Energy., Applied Mechanics and Materials, 725-726, pp. 1626-1633 (2015)

34. O. Gamayunova, N. Vatin, BIM-technology in architectural design, Advanced Materials Research, 1065-1069, pp. 2611-2614 (2015)

35. A.O. Asojo, Connecting Academia with Industry: Pedagogical Experiences from a Collaborative Design Project, Procedia - Social and Behavioral Sciences, 105, pp. 304-313 (2013)

36. Stefania Fabozzi, Salvatore Antonio Biancardo, Rosa Veropalumbo, Emilio Bilotta, IBIM based approach for geotechnical and numerical modelling of a conventional tunnel excavation, Tunnelling and Underground Space Technology, Volume 108 (2021)

37. Felix Hegemann, Janosch Stascheit, Ulrich Maidl, As-built documentation of segmental lining rings in the BIM representation of tunnels, Tunnelling and Underground Space Technology, Volume 106 (2020)

38. Pedram Ghannad, Yong-Cheol Lee, Johannes Dimyadi, Wawan Solihin, Automated BIM data validation integrating open-standard schema with visual programming language, Advanced Engineering Informatics, Volume 40, Pages 14-28 (2019)

39. Rui He, Mingkai Li, Vincent J.L. Gan, Jun Ma, BIM-enabled computerized design and digital fabrication of industrialized buildings: A case study, Journal of Cleaner Production, Volume 278 (2021)

40. Filip Biljecki, Joie Lim, James Crawford, Diana Moraru, Helga Tauscher, Amol Konde, Kamel Adouane, Simon Lawrence, Patrick Janssen, Rudi Stouffs, Extending CityGML for IFC-sourced 3D city models, Automation in Construction, Volume 121 (2021)

41. Huaquan Ying, Sanghoon Lee, A rule-based system to automatically validate IFC second-level space boundaries for building energy analysis, Automation in Construction, Volume 127 (2021) 
42. Huaquan Ying, Sanghoon Lee, Generating second-level space boundaries from largescale IFC-compliant building information models using multiple geometry representations, Automation in Construction, Volume 126 (2021)

43. Junxiang Zhu, Xiangyu Wang, Peng Wang, Zhiyou Wu, Mi Jeong Kim, Integration of BIM and GIS: Geometry from IFC to shapefile using open-source technology, Automation in Construction, Volume 102, Pages 105-119 (2019)

44. Hao Wang, Yisha Pan, Xiaochun Luo, Integration of BIM and GIS in sustainable built environment: A review and bibliometric analysis, Automation in Construction, Volume 103, Pages 41-52 (2019) 